Е. Ю. Башкуева. Работа Министерства здравоохранения Республики Бурятия с жалобами и обращениями граждан как индикатор качества работы органа исполнительной власти...

Научная статья

УДК 614.253 .83

DOI 10.18101/2304-4446-2020-4-33-43

\title{
РАБОТА МИНИСТЕРСТВА ЗДРАВООХРАНЕНИЯ РЕСПУБЛИКИ БУРЯТИЯ С ЖАЛОБАМИ И ОБРАЩЕНИЯМИ ГРАЖДАН КАК ИНДИКАТОР КАЧЕСТВА РАБОТЫ ОРГАНА ИСПОЛНИТЕЛЬНОЙ ВЛАСТИ: СОСТОЯНИЕ И ПРОБЛЕМЫ
}

\author{
(C) Башкуева Елена Юрьевна \\ кандидат исторических наук, \\ Бурятский научный центр СО РАН \\ Россия, 670047, г. Улан-Удэ, ул. Сахьяновой, 8 \\ frombear@mail.ru
}

\begin{abstract}
Аннотация. В статье представлен анализ работы Министерства здравоохранения Республики Бурятия с жалобами и обращениями граждан. Материалами исследования послужили ведомственные данные Министерства здравоохранения Республики Бурятия по работе с жалобами и обращениями граждан (отчетные данные за 2015-2019 гг., тексты жалоб и обращений за 2019 г.), материалы экспертных интервью с руководством и специалистами Министерства здравоохранения Республики Бурятия $(\mathrm{N}=5)$. Исследование базировалось на синтезе следующих методов: аналитического, статистического, SWOT-анализа, метода экспертных оценок. За пятилетний период (20152019 гг.) выявлено снижение общего количества обращений граждан при росте жалоб на качество медицинской помощи, нарушения этики и деонтологии. Выполнен SWOT-анализ, выявлены сильные и слабые стороны работы министерства в обозначенном направлении. Предложены механизмы повышения эффективности работы Министерства здравоохранения Республики Бурятия с жалобами и обращениями граждан.

Ключевые слова: жалоба; обращение; Министерство здравоохранения; медицинская организация; качество; безопасность; медицинское обслуживание; этика; деонтология; поликлиника; больница; Республика Бурятия.
\end{abstract}

\section{Для цитирования}

Башкуева Е. Ю. Работа Министерства здравоохранения Республики Бурятия с жалобами и обращениями граждан как индикатор качества работы органа исполнительной власти: состояние и проблемы // Вестник Бурятского государственного университета. Экономика и менеджмент. 2020. № 4. С. 33-43.

Право каждого человека на охрану здоровья и медицинскую помощь является общепризнанной нормой международного права и закреплено в основном законе - Конституции Российской Федерации.

Письменные обращения граждан в органы государственной власти, наделенные функциями контроля и надзора в области качества и безопасности медицинской деятельности, являются наиболее массовым и доступным способом защиты права на охрану здоровья.

Особенности работы с обращениями граждан по вопросам оказания медицинской помощи в государственные органы управления и медицинские организа- 
ции рассматривали в своих работах Д. А. Бугаев [1], А. Р. Гайсина и Н. Х. Шарафутдинова [2] Д. В. Пивень с соавторами [4], Т. Г. Светличная с соавторами [5; 6], О. В. Ходакова [8] , Т. И. Хохрина [9] и ряд других исследователей и организаторов здравоохранения.

Что касается мировых тенденций, M. Dixon-Woods, S. McNicol, G. Martin отмечают, что в секторе здравоохранения вопросы безопасности и качества медицинской помощи составляют $33,7 \%$ всех жалоб, вопросы, связанные с управлением (процессы, связанные с приемом, выпиской, выставлением счетов, финансами, обращениями) - 35,1\%, а также проблемы в отношениях между персоналом и пациентом (поведение, коммуникация) - 29,1\%. Мировым трендом является повышение вовлеченности пациентов в совершенствование качества медицинской помощи, причем сами системы здравоохранения развитых стран заинтересованы в использовании различных способов получения обратной связи с пациентами, в том числе на основе современных технологий ( смс сообщения, работа колл-центров, социальных сетей и др.) [10].

Работа с обращениями и жалобами граждан является системной проблемой российского здравоохранения как на федеральном, так и на региональном уровнях.

В 2019 г. в Министерство здравоохранения Российской Федерации (далее министерство, Минздрав России) поступило и было рассмотрено более 156 тысяч письменных и устных обращений граждан, что на $4,7 \%$ больше по сравнению с предыдущим 2018 г. В 2019 г. сохранилась устойчивая тенденция превалирования количества электронных обращений граждан над письменными, что обусловлено имеющейся возможностью направления обращений в министерство через общественную интернет-приемную, размещенную на официальном сайте Минздрава России, и направление электронных обращений на официальный электронный адрес министерства: info@ rosminzdrav.ru1 .

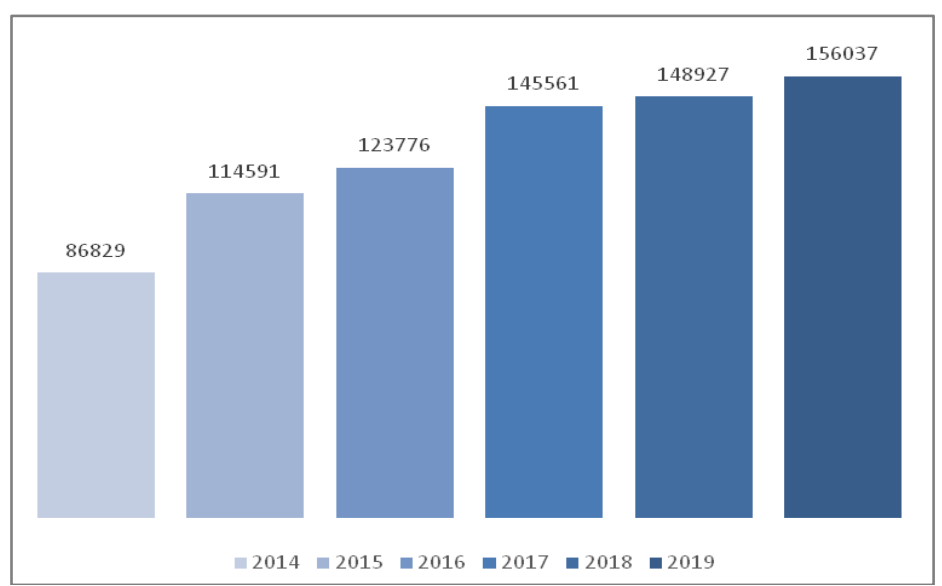

Рис. 1. Динамика письменных и устных обращений граждан в Министерство здравоохранения Российской Федерации (2014-2019 гг.) 2

\footnotetext{
${ }^{1}$ Итоги работы с обращениями граждан в Министерстве здравоохранения Российской Федерации в 2019 г. [Электронный ресурc]. URL: https://minzdrav.gov.ru/reception/stat (дата обращения: 10.09.2020).

${ }^{2}$ Там же.
} 
Е. Ю. Башкуева. Работа Министерства здравоохранения Республики Бурятия с жалобами и обращениями граждан как индикатор качества работы органа исполнительной власти...

По данным рис. 1, в целом за 6 лет прослеживается устойчивая динамика роста обращений граждан в Министерство здравоохранения РФ, рост составил $79,7 \%$.

С целью оценки работы Министерства здравоохранения Республики Бурятия в обозначенном направлении в 1-м полугодии 2020 г. нами было проведено независимое исследование. Материалами исследования послужили ведомственные данные Министерства здравоохранения Республики Бурятия по работе с жалобами и обращениями граждан (отчетные данные за 2015-2019 гг., тексты жалоб и обращений за 2019 г.), материалы экспертных интервью с руководством и специалистами Министерства здравоохранения Республики Бурятия $(\mathrm{N}=5)$, проведенных в 1-м полугодии 2020 г. Исследование базировалась на синтезе следующих методов: аналитического, статистического, SWOT-анализа, метода экспертных оценок.

В Министерстве здравоохранения Республики Бурятия существует отдел по работе с обращениями граждан, в составе которого 2 специалиста. В ходе экспертных интервью с данными работниками выявлено, что этого штата не хватает для осуществления всего объема работы и специалистам постоянно приходится трудиться сверхурочно.

Установлено, что работа специалистов Министерства здравоохранения с обращениями осуществляется в соответствии с требованиями Федерального закона «О порядке рассмотрения обращений граждан Российской Федерации» и другими ФЗ и нормативно-правовыми актами.

Проведенный нами анализ обращений граждан в региональный Минздрав за пять лет, с 2015 по 2019 г., несмотря на положительную динамику снижения обращений граждан, показывает, что сохраняется тенденция некоторого роста жалоб на качество медицинской помощи, нарушение этики и деонтологии на $40 \%$ с 618 в 2015 г. до 866 в 2019 г. (табл. 1).

Таблица 1 Количество обращений и жалоб в Минздрав Республики Бурятия за 2015-2017 гг.

\begin{tabular}{|l|c|c|c|}
\hline \multicolumn{1}{|c|}{ Наименование } & 2015 & 2017 & 2019 \\
\hline $\begin{array}{l}\text { Количество обращений и жалоб всего, } \\
\text { в т. ч. }\end{array}$ & 2925 & 2335 & 2627 \\
\hline $\begin{array}{l}\text { Жалобы на качество оказания меди- } \\
\text { цинской помощи, нарушение этики и } \\
\text { деонтологии }\end{array}$ & 618 & 546 & 866 \\
\hline
\end{tabular}

Источник: ведомственные данные Министерства здравоохранения Республики Бурятия

Выполнен анализ работы Министерства здравоохранения Республики Бурятия с жалобами и обращениями граждан (за 2019 г.) с целью оценки полноты и эффективности системы реагирования на обращения граждан. Выборочно изучены тексты ответов на обращения граждан (свыше 50\% от всего массива), что позволило сделать обоснованные выводы и сформулировать предложения по совершенствованию работы Министерства здравоохранения РБ в обозначенном направлении. 
По данным Министерства здравоохранения РБ, за 2019 г. поступило 2627 обращений. Структура обращения представлена следующим образом:

- качество оказания медицинской помощи: 824 обращения. Наибольшее количество жалоб на ГАУЗ «Заиграевская ЦРБ», ГАУЗ «Городская больница № 4», ГАУЗ «Городская поликлиника № 6», ГАУЗ «Городская поликлиника № 2», ГБУЗ «Иволгинская центральная районная больница». Отмечаются низкий профессиональный уровень медицинских работников, несвоевременное оказание медицинской помощи, нанесение ущерба здоровью, несвоевременно и неправильно поставленные диагнозы, приводившие к ухудшению состояния здоровья пациентов вплоть до летальных исходов, врачебные ошибки. Вопиющие факты халатности медицинского персонала, имевшие большой общественный резонанс и нанесшие огромный удар по репутации Министерства здравоохранения РБ и здравоохранению РБ, были допущены в Баргузинской ЦРБ (дело В. Колмакова ${ }^{1}$ ) и в Детской клинической больнице (ныне ДРКБ) в связи с делом Захара Котенко ${ }^{2}$.

- вопросы доступности медицинской помощи, трудности записи на прием к специалистам: 326 обращений. Наибольшее количество жалоб на ГБУЗ «Городская поликлиника № 6», ГАУЗ «Городская поликлиника № 2», ГАУЗ «Городская поликлиника № 1 » и ГБУЗ «Городская поликлиника № 1».

Анализ обращений и жалоб граждан показал, что отмечаются многочисленные сбои в работе электронной системы записи пациентов (особенно к узким специалистам).

- обращения на нарушения этики и деонтологии: 42 обращения. Наибольшее количество обращений по этому вопросу на ГАУЗ «Кабанская ЦРБ», ГБУЗ «Городская поликлиника № 6», ГБУЗ «Кяхтинская ЦРБ». Характерно, что при проведении проверок и внутреннего контроля эти жалобы не подтверждаются и это ставит эксперта в тупик - либо они действительно были не обоснованны, либо признаны необоснованными в интересах медицинских работников. Однако их постоянный характер все же свидетельствует о наличии проблемы и необходимости разработки корректирующих действий в данном направлении.

- обращения по заработной плате медицинских работников: 28. ГАУЗ «БСМП», ГБУЗ «Республиканский противотуберкулезный диспансер», ГБУЗ «Гусиноозерская ЦРБ». Многие обращения самих медиков носят анонимный характер, что свидетельствует о нездоровом психологическом климате в медицинских организациях, боязни увольнений и репрессий. Считаем, что по фактам обращений медицинских работников помимо общей проверки следует провести дополнительные процедуры с использованием новых методов (замеры психологического климата, фокус-группы и др.).

\footnotetext{
${ }^{1}$ Главного врача больницы в Бурятии, в которой умер запертый в палате на замок пациент, уволили [Электронный ресурc]. URL: https://www.irk.kp.ru/daily/26965/4020604/ (дата обращения: 10.09.2020).

${ }^{2}$ Ошибки бурятских врачей при лечении младенца от бронхита довели его до комы [Электронный ресурс]. URL: https://doctor.rambler.ru/pharma/42095049-oshibki-buryatskihvrachey-pri-lechenii-mladentsa-otbronhita-doveli-ego-do-komy (дата обращения: 12.09.2020).
} 
Е. Ю. Башкуева. Работа Министерства здравоохранения Республики Бурятия с жалобами и обращениями граждан как индикатор качества работы органа исполнительной власти...

- обращения по поводу неудовлетворительных материально-технических условий: 19. На ГАУЗ «Кабанская ЦРБ», ГБУЗ «Тункинская центральная районная больница».

- обращения по кадровому дефициту: 12, все по ГБУЗ «Кяхтинская ЦРБ».

Остальные 1376 обращений были представлены по другим причинам (лекарственное обеспечение, вопросы высокотехнологичной медицинской помощи, взимание денежных средств за медицинскую помощь по программам ОМС на территории страхования и др.)

Выявлено, что существенный массив обращений связан с проблемами лекарственного обеспечения льготных категорий граждан (пациенты с сахарным диабетом, дети до 3-х лет, инвалиды и др.), что свидетельствует о больших упущениях в работе Министерства здравоохранения и подведомственных организаций в данном направлении.

Установлено, что сотрудниками Министерства здравоохранения РБ отчеты о работе с обращениями ведутся поверхностно, отсутствует их полноценный количественный и качественный анализ (сравнение с предыдущими данными, расчет удельного веса обращений по причинам в общей структуре обращений и др.), а также разработка корректирующих действий. Ответы заявителям зачастую носят характер формальных отписок. Допускаются даже орфографические и стилистические ошибки в текстах ответов специалистов Министерства здравоохранения РБ, что недопустимо для работы чиновников такого уровня.

Обращения граждан перенаправлялись из следующих органов власти: Министерство здравоохранения Российской Федерации, администрация Президента РФ, Общественная палата РФ, администрация Главы и Правительства Республики Бурятия, Народный Хурал Республики Бурятия, ТУ Росздравнадзора по Республике Бурятия, Аппарат уполномоченного по правам человека в Республике Бурятия, Аппарат уполномоченного по правам ребенка в Республике Бурятия, Министерство социальной защиты населения Республики Бурятия. По источникам обращений аналитическая работа специалистами Министерства здравоохранения РБ не ведется. На наш взгляд, причины обращения заявителей в органы власти более высокого (федерального и регионального) уровня (Министерство здравоохранения Российской Федерации, администрация Президента РФ, Общественная палата РФ, администрация Главы и Правительства Республики Бурятия, Народный Хурал Республики Бурятия и др.) обусловлены тем, что заявители опасаются напрямую обращаться в само Министерство здравоохранения РБ и таким образом имеют рычаг воздействия на само министерство через органы власти федерального и регионального уровней (иными словами, «подстраховываются»), что свидетельствует о невысоком уровне доверия граждан к деятельности самого министерства.

Выявлено отсутствие обязательных стандартов качества ответа на обращения граждан. Многие исследователи и организаторы здравоохранения отмечают, что существуют пробелы российского законодательства в данном контексте [4; 8; 9]. К сожалению, в законе нет конкретных критериев качества, поэтому каждый специалист отвечает так, как считает правильным. Безусловно, специалисты Министерства здравоохранения Республики Бурятия стараются соблюдать все нормы российского законодательства, осуществляют разборы по каждому обра- 
щению. Однако не решаются корневые проблемы, по которым обращаются заявители (недостаток специалистов, особенно в сельских районах РБ, их низкие компетенции, низкий уровень этики и деонтологии в МО, проблемы с записью к специалистам в связи со сбоями электронных систем).

Выявлен низкий уровень правовых знаний самих заявителей, которые не знают, как грамотно составить текст обращения, не указывают в них важнейшую информацию, в том числе касающуюся самих заявителей и лиц, в интересах которых они действуют (ФИО, пол, возраст, полные контактные данные: почтовый адрес, телефон, электронная почта), медицинских учреждений, в которые они обращаются (полное юридическое наименование, местонахождение), медицинского персонала (ФИО, должность), который обусловил обращение заявителя. Это приводит к тому, что специалистам Министерства здравоохранения Республики Бурятия невозможно провести полноценную проверку по фактам, изложенным в обращении. Вместе с тем на сайте Министерства здравоохранения отсутствует информация, как правильно составить заявление, какие данные необходимо указать в обязательном порядке. Нами предложено разработать памятку для граждан по составлению обращений в Министерство здравоохранения Республики Бурятия и подведомственные учреждения, разместить ее в свободном доступе на сайте и в других информационных ресурсах.

Следует провести организационную и методическую работу по совершенствованию делопроизводства отдела по работе с обращениями граждан Министерства здравоохранения Республики Бурятия. Провести при необходимости обучение его специалистов, расширить, если это возможно, штат. Рекомендовано специалистам Министерства здравоохранения РБ посетить другие министерства и ведомства, в том числе за пределами Республики Бурятия, перенять их опыт.

Целесообразно совершенствовать нормативную базу по работе с обращениями, в том числе подготовить новую инструкцию по работе с жалобами и обращениями граждан в Министерство здравоохранения Республики Бурятия с учетом всех норм федерального законодательства. Действующий в настоящее время Порядок организации работы с обращениями граждан в Министерстве здравоохранения Республики Бурятия требует существенной модернизации.

Считаем, что существует необходимость разработать и утвердить внутренние стандарты качества ответов на обращения граждан. Имеет смысл разработать определенные шаблоны ответов, с использованием речевых клише (модулей). Крайне востребовано было бы, на наш взгляд, разработать универсальное методическое пособие по работе с обращениями граждан с учетом федерального и регионального опыта.

На наш взгляд, в целях повышения качества работы министерства в обозначенном направлении целесообразно комиссионно проводить ежеквартальный анализ ответов на предмет соответствия действующему законодательству с привлечением главных специалистов-экспертов МЗ РБ и юристов.

Для совершенствования работы с обращениями граждан специалистам министерства целесообразно изучить лучший мировой и российский опыт в этом направлении. Считаем, что методической информации достаточно в сети Интернет. При необходимости можем оказать помощь в ее поиске и систематизации. 
Е. Ю. Башкуева. Работа Министерства здравоохранения Республики Бурятия с жалобами и обращениями граждан как индикатор качества работы органа исполнительной власти...

Например, достаточно информативен сайт Министерства здравоохранения Республики Татарстан, где есть отдельная вкладка по работе с обращениями. На ней есть такие сервисы, как «проверка статуса сообщения», «бесплатная юридическая помощь», и много другой полезной информации и примеров эффективной работы. Что мешает специалистам Министерства здравоохранения РБ изучить лучшие отечественные практики и использовать в своей работе такой опыт? Конечным итогом было бы только улучшение показателей работы министерства и снижение числа негативных отзывов со стороны граждан.

Выявлен недостаточный уровень просветительской и разьяснительной деятельности Министерства здравоохранения Республики Бурятия по обращениям граждан в СМИ и сети Интернет.

На основании проведенного исследования осуществлен SWOT-анализ деятельности Министерства здравоохранения РБ по работе с обращениями граждан (таблица 2).

Таблица 2

Матрица SWOT-анализа

\begin{tabular}{|c|c|}
\hline Сильные стороны & Слабые стороны \\
\hline $\begin{array}{l}\text { 1) Министерство здравоохранения РБ - госу- } \\
\text { дарственный орган исполнительной власти вто- } \\
\text { рого уровня государственного управления. } \\
\text { 2) вступление в силу Федерального закона от } \\
\text { 02.05.2006 г. № 59-ФЗ «О порядке рассмотрения } \\
\text { обращений граждан Российской Федерации», } \\
\text { который регламентирует организацию работы в } \\
\text { данной сфере }\end{array}$ & $\begin{array}{l}\text { 1) низкий уровень системной работы Мини- } \\
\text { стерства здравоохранения Республики Бурятия } \\
\text { 2) отсутствие должностных инструкций и мат- } \\
\text { рицы ответственности у сотрудников Министер- } \\
\text { ства здравоохранения РБ } \\
\text { 3) низкая эффективность правовых и органи- } \\
\text { зационных мер контроля со стороны руковод- } \\
\text { ства. } \\
\text { 4) недостаточная эффективность кадрового } \\
\text { потенциала и недостаточный уровень практиче- } \\
\text { ских навыков у государственных служащих. } \\
\text { 5) Отмечаются случаи поверхностного рассмот- } \\
\text { рения жалоб и обращений граждан. } \\
\text { 6) Слабый уровень взаимодействия с другими } \\
\text { органами исполнительной, законодательной и } \\
\text { судебной власти, а также местного самоуправ- } \\
\text { ления } \\
\text { 7) В работе не используются единые формы } \\
\text { отчетов и аналитики }\end{array}$ \\
\hline Угрозы & Возможности \\
\hline $\begin{array}{l}\text { 1) несовершенство законодательства РФ по } \\
\text { работе с обращениями граждан. } \\
\text { 2) низкая способность управленческих меха- } \\
\text { низмов быстро адаптироваться к постоянно } \\
\text { изменяющимся условиям. } \\
\text { 3) постоянные изменения законодательной } \\
\text { базы. }\end{array}$ & $\begin{array}{l}\text { 1) внедрение единых принципов и стандартов } \\
\text { работы с обращениями граждан. } \\
\text { 2) анализ действующей федеральной и регио- } \\
\text { нальной правовой базы. } \\
\text { 3) разработка и издание методических реко- } \\
\text { мендаций. } \\
\text { 4) создание юридической службы / обществен- } \\
\text { ной приемной, оказывающих консультации по } \\
\text { вопросам медицинской деятельности. }\end{array}$ \\
\hline
\end{tabular}

На основании мнений экспертов и исследования большого массива научной и методической литературы $[1 ; 4 ; 6-9]$ можно предложить несколько основных 
направлений повышения эффективности механизмов реагирования на обращения граждан в Министерство здравоохранения Республики Бурятия, в том числе:

- усилить контроль за направлением качественных ответов в установленные сроки;

- повысить качество рассмотрения заявлений граждан, обратить внимание на полноту и достоверность информации, содержащейся в ответах на обращения;

- осуществить разработку шаблонов ответа на обращение гражданина, которая в обязательном порядке должна содержать основные компоненты качественного ответа, в том числе конкретное решение проблемы, заявленной в обращении, при необходимости принятие мер по устранению выявленных нарушений;

- регламентировать все формы ответственности за нарушения и поверхностный подход к рассмотрению обращения;

- осуществлять выявление обращений первостепенного характера, направленное на обеспечение прав гражданина, в случае если месячный срок рассмотрения может иметь угрозу для здоровья;

- проводить углубленный тематический анализ по направлениям обращений граждан с выделением и разбором актуальных вопросов с результатами их рассмотрения и принятых мер и осуществлять рассмотрение наиболее важных «корневых» проблем, поднятых заявителями, на рабочих совещаниях;

- публиковать краткие работы Министерства здравоохранения РБ в виде дайджестов на официальном сайте Министерства здравоохранения РБ;

- внедрить механизм автоматического уведомления заявителей о получении и номере регистрации обращения, направленного в электронном виде, отслеживания процесса и результатов рассмотрения;

- публиковать ответы на часто задаваемые вопросы с привлечением главных специалистов-экспертов МЗ РБ и начальников отделов МЗ РБ;

- контактные данные и сведения об ответственных сотрудниках — публиковать на сайте и в социальных сетях;

- проводить анализ принятых решений на основе предложений граждан и общественных организаций;

- предлагаем осуществлять анкетирование заявителей для оценки полноты и качества ответа на обращение;

- предлагаем обсуждение результатов работы с обращениями на совещаниях Межведомственной комиссии по качеству медицинской деятельности, Общественного совета при Министерстве здравоохранения Республики Бурятия;

- учет показателей соблюдения сроков направления ответов на обращения и запросы граждан в показателях оценки деятельности структурных подразделений органа власти;

- проведение выборочного анализа Общественным советом, экспертными и консультативными органами качества ответов на обращения заявителей.

По работе с обращениями также предлагаем:

- разработать систему учета показателей сроков рассмотрения и качества ответов на обращения и запросы граждан для оценки деятельности структурных подразделений Министерства здравоохранения Республики Бурятия и ответственных исполнителей; 
Е. Ю. Башкуева. Работа Министерства здравоохранения Республики Бурятия с жалобами и обращениями граждан как индикатор качества работы органа исполнительной власти...

- разработать и внедрить ведомственные стандарты качества ответов на обращения граждан;

- выполнить углубленный анализ действующих организационных процессов по работе с обращениями граждан и совершенствовать механизмы рассмотрения всех запросов, в том числе направление обращений с вопросами по компетенции других органов или должностных лиц;

- провести оценку коммуникационных компетенций сотрудников Министерства здравоохранения РБ и системы здравоохранения в целом и разработать образовательные и мотивационные программы в этом направлении;

- ввести систему нематериального стимулирования за эффективность работы с обращениями граждан и юридических лиц. В том числе объявление благодарности, публикация (размещение в электронном виде на сайте государственного органа) информации о конкретном должностном лице, эффективно решающем вопросы, связанные с обращениями граждан.

Также предлагаем ввести балльную и количественную оценку по каждому заявлению и жалобе и ежеквартально составлять отчетность по этим показателям (таблица 3).

Таблица 3

Показатели для балльной и количественной оценки эффективности работы с обращениями

\begin{tabular}{|l|l|}
\hline 1) соблюдение сроков ответа & максимально 10 баллов \\
\hline 2) всесторонность и объективность рассмотрения обращения & максимально 10 баллов \\
\hline 3) правовая обоснованность принятого решения & максимально 10 баллов \\
\hline $\begin{array}{l}\text { 4) ответы содержат общие разъяснения нормативно-правовых } \\
\text { актов }\end{array}$ & количество \\
\hline $\begin{array}{l}\text { 5) ответы содержат конкретные решения и подробные, понят- } \\
\text { ные рекомендации }\end{array}$ & количество \\
\hline 6) ответы даны не по сути вопроса заявителя & количество \\
\hline 7) приняты меры, решающие вопросы заявителя & количество \\
\hline $\begin{array}{l}\text { 8) приняты меры, но требуется дополнительный контроль их } \\
\text { исполнения }\end{array}$ & количество \\
\hline $\begin{array}{l}\text { 9) ответы содержат формальные разъяснения, вопрос заявителя } \\
\text { не решен }\end{array}$ & количество \\
\hline
\end{tabular}

Таким образом, Министерству здравоохранения Республики Бурятия предстоит большая и кропотливая работа по совершенствованию своей деятельности с обращениями и жалобами граждан. Важнейшим фактором снижения количества обращения и жалоб станет решение корневых проблем регионального здравоохранения - кадровых, организационных, материально-технических, и прежде всего вопросов доступности и качества медицинской помощи.

\section{Литература}

1. Бугаев Д. А. Анализ письменных обращений граждан с жалобами на организацию специализированной травматолого-ортопедической помощи и результатов целевой экспертизы качества медицинской помощи // Социальные аспекты здоровья населения. 2019. T. 65 , № 3. C. 10-15. 
2. Гайсина А. Р., Шарафутдинова Н. Х. Жалобы граждан на нарушение их прав при получении медицинской помощи // Международный научно-исследовательский журнал. 2017. № 4(58). С. 148-152.

3. Захаренко Г. А., Белокопытова Н. В., Салагай О. О. Проблемы работы горячих линий в здравоохранении // Проблемы социальной гигиены, здравоохранения и социальной медицины. 2020. Т. 20, № 2. С. 303-305.

4. Пивень Д. В., Кицул И. С., Иванов И. В. Работа с обращениями граждан и удовлетворение отдельных требований потребителя: что необходимо учитывать медицинским организациям // Менеджер здравоохранения. 2019. № 9. С. 77-81.

5. Светличная Т. Г., Цыганова О. А., Зинькевич В. К. Медико-правовой анализ обращений пациентов в государственные и муниципальные органы // Экология человека. 2010. № 2. С. 50-53.

6. Светличная Т. Г., Цыганова О. А., Зинькевич В. К. Обеспечение прав пациентов в условиях городского здравоохранения Заполярья: медико-социологический анализ. Архангельск: Изд-во Северного гос. мед. ун-та, 2012. 169 с.

7. Филиппов Ю. Н. Работа с письменными обращениями населения как одно из направлений деятельности территориального органа управления здравоохранением с целью повышения качества медицинской помощи // Самарский медицинский журнал. 2007. № 1-2(35-36). С. 65-67.

8. Ходакова О. В. Организационно-правовое регулирование в системе управления качеством медицинской помощи на территориальном уровне: автореф. дис. ... д-ра мед. наук. Кемерово, 2014. 43 с.

9. Хохрина Т. И. Организация работы с обращениями граждан в учреждениях здравоохранения // Правовые вопросы в здравоохранении. 2013. № 4. С. 30-42.

10. Dixon-Woods M., McNicol S., Martin G. Ten challenges in improving quality in healthcare: lessons from the Health Foundation's programme evaluations and relevant literature // BMJ Qual Saf. 2012. April 28. P. 876-884.

\title{
WORK OF THE MINISTRY OF HEALTH OF THE REPUBLIC OF BURYATIA WITH PUBLIC APPEALS AS AN INDICATOR OF THE EXECUTIVE AUTHORITIES PERFORMANCE: CURRENT STATE AND CHALLENGES
}

\author{
Elena Yu. Bashkueva \\ Cand. Sci. (History), \\ Buryat Scientific Center SB RAS \\ 8 Sakhyanovoy St., Ulan-Ude 670047, Russia \\ frombear@mail.ru
}

Abstract. The article analyzes the work of the Ministry of Health of the Republic of Buryatia with public complaints and appeals. Study material include proprietary data of the Ministry of Health of the Republic of Buryatia on work with public complaints and appeals (reports for 2015-2019, texts of complaints and appeals for 2019), expert interviews with administration and staff of the Ministry of Health of the Republic of Buryatia $(\mathrm{N}=5)$. The research is based on the synthesis of the following methods: analytical, statistical, SWOT-analysis, method of expert assessments. Over a five-year period (2015-2019) it has been revealed a decrease in the total number of public appeals with an increase in complaints about the quality of medical care, violations of ethics and deontology. We have carried out a SWOTanalysis, identified the strengths and weaknesses of the ministry's work with public appeals. 
Е. Ю. Башкуева. Работа Министерства здравоохранения Республики Бурятия с жалобами и обращениями граждан как индикатор качества работы органа исполнительной власти...

In the article we propose the mechanisms for increasing the efficiency of the Ministry of Health of the Republic of Buryatia in work with public complaints and appeals.

Keywords: complaint; appeal; the Ministry of Health; healthcare organization; quality; safety; medical care; ethics; deontology; polyclinic; hospital; the Republic of Buryatia.

Статья поступила в редакцию 21.10.2020; одобрена после рецензирования 30.10.2020; принята к публикации 30.10.2020. 